\title{
Mujeres y movimiento negro afromexicano a través de la historia de vida
}

\author{
Itza Amanda Varela Huerta' (iD) 0000-0003-3160-7481 \\ 'El Colegio de México, Ciudad de México, México. \\ 14110-coordinacion.pieg@colmex.mx
}

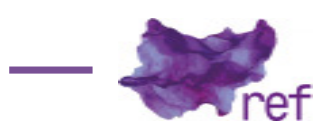

Resumen: El objetivo de este artículo es describir y analizar el proceso de construcción de una subjetividad política negra-afromexicana a partir de la historia de vida de la activista e intelectual negra-afromexicana Juliana Acevedo (1979). Esta narración se enmarca en el proceso político por el cual algunas mujeres afro construyeron desde 2012 un espacio de enunciación política generizado respecto a la identidad etnizada a finales del siglo XX y XXI en la Costa Chica mexicana. Pretendo dar cuenta de que Acevedo, como un ejemplo de las mujeres activistas e intelectuales, construye su diferencia dentro y fuera del movimiento afrodescendiente en cuanto a las intersecciones de racialización, clase y género para cuestionar las formas históricas y políticas mediante las cuales han sido representadas, así como exponer las marcas del discurso feminista en su narración.

Palabras clave: agencia; subjetividades; feminismos; narrativas; afrodescendientes

Afro-Mexican Women and The Black Movement through Life History

Abstract: This article describes and analyzes the process of building Black-Afro Mexican political subjectivity through the life history of Black-Afro Mexican activist and intellectual Juliana Acevedo. This narration emerges from within a political process which began in 2012, in which Afro women built a space for gendered political enunciation regarding ethnicized identity at the end of the 20th and beginning of the 21st Century. Acevedo is part of a tradition of engaged women intellectuals who delineate difference within and outside of the Afro-descendent movement. Her narration interrogates feminist discourse and questions the historical and political forms and the intersections of racialization, class, and gender within which intellectual and activist Black-Afro Mexican women have been represented.

Keywords: Afro-descendants; Narratives; Feminism; Agency; Subjectivities

Mulheres afro-mexicanas e movimento negro através da história de vida

Resumo: O objetivo deste artigo é descrever e analisar o processo de construção de uma subjetividade política negra-afro-mexicana a partir da história de vida da intelectual e ativista negra-afro-mexicana Juliana Acevedo (1979). Essa narrativa se enquadra no processo político pelo qual algumas mulheres afro construíram desde 2012 um espaço de enunciação política de gênero sobre a identidade étnica no final dos séculos XX eXXI na Costa Chica mexicana. Pretendo perceber que Acevedo, a exemplo de mulheres ativistas e intelectuais, constrói sua diferença dentro e fora do movimento afrodescendente em termos das intersecções de racialização, classe e gênero para questionar as formas históricas e políticas pelas quais foram representadas, além de expor as marcas do discurso feminista em sua narração.

Palavras-chave: afrodescendentes, narrativas, feminismo, agência, subjetividades 


\section{Introducción}

La presente historia de vida busca analizar, por un lado, cómo se constituyó una subjetividad específica dentro del movimiento de mujeres enmarcado en el proceso político negro-afromexicano' y para eso, indago en la construcción del pasado de dicha movilización política que con apenas 30 años de existencia ha marcado el curso de vida de diferentes mujeres en la región. Abordo el caso específico de Juliana Acevedo Ávila (Oaxaca, México, 19 de junio de 1979) quien desde su adolescencia participa en su comunidad para mejorar las condiciones de existencia de los diferentes pueblos de la región Costa Chica de Oaxaca.

Este artículo utiliza la entrevista a profundidad para la elaboración de la historia de vida como metodología cualitativa de las ciencias sociales, así como información recabada en charlas informales y en participaciones políticas de Juliana Acevedo Ávila en el Foro por el Reconocimiento de las Mujeres Afrolatinoamericanas realizado en julio de 2018 en Collantes, Oaxaca (México). A través de preguntas específicas sobre el curso de vida de Acevedo Ávila se entrelazarán la constitución y cambios en el movimiento negro-afromexicano, así como los efectos del activismo y la participación política por parte de Acevedo, como mujer joven con historial de activismo. Con la historia de vida, pretendo analizar cuestiones inherentes a la constitución de las políticas de lo femenino, la marca de los feminismos entre mujeres activistas e intelectuales que se autoadscriben como negras-afromexicanas, y los elementos de la diferencia étnica que constituye su narración diferenciada.

Aunque la historia de vida es una metodología que permite narrar de manera particular los cambios y perspectivas de diferentes sujetos sociales en tiempos específicos, ha sido poco utilizada en el ámbito de los estudios afromexicanistas, puntualmente en la antropología, disciplina que ha centrado sus trabajos en la etnografía como forma específica de acercamiento a estas poblaciones. Para este trabajo, pienso junto con Franco Ferrarotti que "La historia de vida puede ser vista, desde esta perspectiva, como una contribución esencial a la memoria histórica, a la inteligencia del contexto" (FERRAROTTI, 2007, p. 28) y por esto me concentro en Juliana Acevedo como sujeto fundamental para comprender el proceso político negro-afromexicano.

Siguiendo la idea anterior, argumento que la historia de vida es una metodología que permite analizar desde una condición subjetiva preguntas más complejas que, entretejiéndolas e hilvanándolas con los contextos e historias específicas, dan cuenta de un momento social particular:

La originalidad de la historia de las mujeres -observó Ana Lida García (1998)- están en el tipo de preguntas que formula. Son preguntas que hacen visibles a las mujeres como sujetos históricos inmersos en una circunstancia particular que las conforma, a la vez que ellas actúan sobre esta" (p. 200) Las condiciones de vida de las mujeres (y también de las minorías) diferían mucho del hombre heterosexual (blanco), sujeto de la biografía tradicional, Para Blanche Wiese Cook, reconocida biógrafa de Eleanor Roosevelt, fueron "las feministas (que) efectuaron una revolución en la biografía. Planteamos preguntas diferentes, distinguimos otros problemas, buscamos secretos y tomamos en serio cuestiones del deseo y la pasión". (Francie CHASSEN-LÓPEZ, 2018, p. 147)

\section{Los inicios del movimiento político negro-afromexicano}

En este apartado hago un breve recorrido sobre los primeros espacios discursivos y de acción política en la Costa Chica de Oaxaca. En diversos foros y eventos relacionados con el proceso político de los pueblos negros-afromexicanos siempre se menciona al padre Glynn Jemmott como el impulsor de la conciencia étnica de la población en la Costa Chica de Oaxaca en México. También se nombra, entre otras personas, a los profesores Sergio Peñaloza e Israel Reyes como integrantes de la primera generación de costeños que empezaron el movimiento hacia la construcción de una etnicidad diferenciada a la indígena en la zona entre Guerrero y Oaxaca a finales de los años 90 del siglo XX; aún hacia finales de la primera década de los 2000 Peñaloza, Reyes Larrea y otros varones fueron los activistas más visibles de las diversas plataformas políticas, por lo cual fue común escuchar sus voces en relación con la primera ola de demandas del naciente movimiento.

Además de las demandas políticas específicas, Jemmott, Peñaloza, Reyes Larrea y otros activistas empezaron a discutir y debatir qué significaba enunciarse como negros, afromexicanos o afromestizos en México a finales del siglo XX, y en la Costa Chica en particular. Y siguiendo la línea argumental de esos primeros años, se buscó demostrar que dichos pueblos tenían una identidad cultural diferenciada, un territorio demarcado, y haber habitado el territorio nacional actual antes de la concreción de sus fronteras, en el sentido que expresa el convenio 169 de la Organización Internacional del Trabajo (OIT).

\footnotetext{
' El movimiento negro-afromexicano inicia a finales de los años 90 en la región de Costa Chica en México (ubicada al sur del país, en los estados de Guerrero y Oaxaca). Y durante más de 20 años fue liderada y presentada al país por varones de mediana edad, quienes exponían las demandas generales de dicha población y asumían la vocería general de la movilización política. A partir de 2012, las organizaciones exclusivas de mujeres, y para atacar problemáticas de mujeres, se han multiplicado por diversos motivos que explicaré en el cuerpo del texto.
} 
Retomando las nociones de Agustín Lao Montes (2009) sobre los diferentes ciclos de movilización afrodescendiente en América Latina, podemos observar que México llega de forma tardía a los procesos político-identitarios latinoamericanos, dado que éstos iniciaron a principios de los años 80 del siglo XX en países como Colombia, Venezuela y Brasil, entre otros más. Pese a que en México la formación de una alteridad negra-afrodescendiente solo inicia a finales de los años 90 , ésta tiene elementos en común con otros movimientos afros en el continente y se adhiere a los convenios internacionales sobre políticas de justicia y reparación respecto a la esclavitud y lucha global contra el racismo ${ }^{2}$, pero solo en el ámbito de las asociaciones civiles y no como un movimiento social autónomo.

Para el tema específico de la lucha de las mujeres afrolatinoamericanas, en México podemos rastrear el activismo de éstas desde el inicio de la movilización, si ampliamos nuestra noción de participación política más allá de los marcos clásicos que implicarían solo la palabra y la militancia activa, si en cambio pensamos desde la teoría feminista (Silvia FEDERICl, 2010; Silvia L. GIL, 2011 ; Amaia PÉREZ OROSCO, 2014; Mariana MIRANDA, 2012) que la participación política así como el trabajo implican otros elementos como la construcción de la vida en común, el trabajo de cuidados, el trabajo afectivo, la logística para construir espacios políticos, etcétera.

Sin embargo y atendiendo a las nuevas formas de pensar lo político y la historia pública, me parece fundamental escribir sobre aquellas personas que no aparecen en el relato o la historia reciente del proceso político de las comunidades afromexicanas o negras y que en los últimos cinco años han sido fundamentales no sólo para el movimiento sino para la generación de una subjetividad negra-afromexicana. Me refiero al activismo de las mujeres, que en este espacio no sólo se ceñirá a las formas clásicas de participación política, sino que lo que pretendo en todo caso es ampliar esta definición. Si bien el Encuentro de Pueblos Negros ${ }^{3}$ es la asamblea que ha perfilado al movimiento afrodescendiente en México como un espacio de discusión sobre el mestizaje, el racismo y las diferentes etnicidades, éste no sería posible sin la participación y cuidado de las mujeres que desde las asambleas, la logística, los cuidados, las cocinas y otros espacios, además de los debates políticos clásicos, permiten y dan sentido a las discusiones sobre lo negro-afromexicano.

En este sentido, feminizar la política no es el significante vacío de pensar la inserción de las mujeres al mundo político institucional como una cuota de los programas contemporáneos de gobernanza, sino pensar desde el feminismo los aportes de sectores históricamente invisibilizados como son las mujeres, los pueblos negros-afromexicanos, la niñez, las personas no heterosexuales, entre otros sujetos históricos en la conformación de los mundos sociales y de los espacios políticos. Es decir, leer desde las claves feministas, en contrapelo a las narraciones hegemónicas de la conformación de las historias recientes, en este caso, de la movilización negra-afromexicana.

Insisto en que tenemos ya no una mirada de feminización de la política, sino aportes feministas a la lucha política negra-afromexicana por parte de algunas mujeres. Lo que interesa en este artículo es notar cómo arribaron a la Costa Chica en el filo del siglo XX los discursos feministas, cuáles han sido sus aportes, pero sobre todo, cómo éstos han sido reelaborados por las activistas e intelectuales de la movilización social, analizando también cuáles son las formas en las que se retroalimenta la construcción de una subjetividad como la de Juliana, y cómo las acciones de Juliana aportan a la discusión sobre los límites y aperturas sobre qué significa una etnicidad negra-afromexicana.

Volviendo a la historia reciente de la movilización negra-afromexicana, podemos mencionar una fecha importante: el primer Encuentro de Pueblos Negros, que se realizó en El Ciruelo, Pinotepa Nacional, Oaxaca en 1997 como una iniciativa civil para discutir cuestiones vinculadas a la propia definición de lo negro, costeño o afromestizo, denominaciones que en ese periodo eran las formas de nombrarse entre la población costeña. El primer encuentro en 1997 dio muestra de procesos comunitarios apuntalados y acompañados por las bases eclesiásticas de la región de Pinotepa Nacional en Oaxaca, así como en procesos políticos de largo aliento en la zona, como señala Gloria Lara:

Para los colectivos de ambas entidades, uno de los intereses centrales era el reconocimiento de "la tercera raíz afromexicana". En ambas entidades el término afromexicano era aceptado por los colectivos, aunque de manera local era común utilizar los términos negro o moreno. En la primera década los referentes que alimentaron y ponderaron en alguna medida los contenidos discursivos de la etnicidad provinieron del sacerdote originario de Trinidad y Tobago, Glyn Jemmott, impulsor y activista de la organización México Negro A.C. y las investigaciones realizadas por

\footnotetext{
${ }^{2}$ Como en el caso de la Conferencia Mundial contra el Racismo, la Discriminación Racial, la Xenofobia y las Formas Conexas de Intolerancia firmada en 2001 en Durban, Sudáfrica.

${ }^{3}$ El Encuentro de Pueblos Negros es una asamblea anual que empezó a realizarse en 1997 para visibilizar a las poblaciones negras-afromexicanas de la Costa Chica. Se realizó desde 1997 en diferentes pueblos de Guerrero y Oaxaca. En 2017, por efectos de la ampliación del movimiento afrodescendiente, éste se llevó a cabo en Veracruz y en 2018 en Coahuila, ambos con población afrodescendiente y activistas vinculados con el proceso en Costa Chica.
} 
antropólogos y otros especialistas nacionales y extranjeros. Al interior de los colectivos organizados se redefinieron líneas de trabajo que trataban de responder a las experiencias planteadas en múltiples reuniones, encuentros y foros dedicados a concientizar sobre los orígenes, la cultura negra y el análisis de las condiciones de vida de la población. El término afromexicano, validado por las instituciones del Estado, formaba parte del discurso de los colectivos organizados, ya que bajo esta categoría étnica en 1998 se reconoció a estas poblaciones en el estado de Oaxaca. En esta primera década (1990) la demanda del reconocimiento constitucional y los contenidos en torno a la discriminación y el racismo aún no cobraban fuerza, las preocupaciones se centraban en la visibilidad y demandas de atención ante la falta de oportunidades, rezago y marginalidad. (LARA, 2014, p.165-166)

De su lado, Juliana Acevedo también señala el papel de la iglesia y las religiones en el proceso político negro-afromexicano:

\begin{abstract}
Me tocaron un montón de cosas de cuando inició el movimiento. Recuerdo, lo primero el centro de producción de radio con Israel (Reyes Larrea), el rescate cultural de la Danza de la Tortuga en Morelos (Oaxaca). Israel (Reyes) estaba yendo a las reuniones con Glynn en 1996 fuera del pueblo y yo estaba más enfocada en la cuestión interna en Morelos, en recuperar esa parte de la identidad a través de las danzas no en la cuestión organizativa del Encuentro de Pueblos Negros. A ese primer Encuentro de Pueblos $N$ yo fui invitada por la iglesia, como era catequista el sacerdote que estaba en ese momento nos llevó como una cuestión religiosa no de rescate de identidad de los pueblos negros, por eso yo insisto siempre en que al principio el movimiento tenía una línea religiosa muy bien marcada, con el tiempo ha ido cambiando, aunque mucha de la metodología sigue siendo la misma. (ACEVEDO, entrevista personal, enero 2019)
\end{abstract}

Es importante pensar los inicios del movimiento por el reconocimiento de los pueblos negrosafromexicanos como espacios de políica situada en los contextos sociales de la región costa de Oaxaca debido a los diferentes actores que se irán fortaleciendo o desvaneciendo en el devenir del proceso. Esto es, entre los actores más influyentes podemos observar a la iglesia católica, a los profesores de diferentes grados escolares vinculados a la Coordinadora Nacional de Trabajadores de la Educación (CNTE), a los activistas sociales que provenían de luchas políticas con otros objetivos (por ejemplo, el exterminio de los cacicazgos de transporte, del coyotaje de productos; las luchas por la implantación de partidos políticos diferentes al Partido Revolucionario Institucional, entre otros). Aunque en este texto me refiero especialmente a la lucha de una mujer, esto no borra que en este momento histórico diferentes mujeres en la Costa Chica, Veracruz, Ciudad de México y Coahuila están construyendo liderazgos políticos y también están contribuyendo a la concreción de la subjetividad negra-afromexicana, que hasta el momento solo había sido enunciada en el mundo académico y el debate público por varones de mediana edad.

En otros escritos académicos se plantea ya la situación de la participación de las mujeres negras-afromexicanas en el proceso político (Mariana MIRANDA, 2012; Itza VARELA, 2017), por lo que aquí traigo la idea de Gayatri Spivak y Santiago Giraldo (2003) en relación con la posibilidad del habla del/ la subalterna: si bien la práctica políica en su dimensión más compleja existía ya entre las mujeres que participaban -como en el caso de las pescadoras de Chacahua (Oax) con las cooperativas de pescadoras que fueron entrevistadas por Mara ALFARO y Gustavo SÁNCHEZ (2002)en diversas organizaciones, la llegada, articulación y puesta en escena del discurso feminista provocó la creación de asociaciones específicas sobre los problemas y la participación políica de las mujeres.

Pienso que es relevante pensar e indagar sobre cuáles son los debates sobre el feminismo que están siendo reelaborados por Juliana Acevedo, quien, a través de los discursos académicos, políticos y jurídicos logra tejer una denuncia específica sobre la situación del pueblo negroafromexicano, posicionándose, así, como una de las activistas e intelectuales más visibles del movimiento, es decir, en diversos círculos su voz queda autorizada.

\title{
Momentos del movimiento negro-afromexicano
}

Con el objetivo de trazar una temporalidad que permita analizar el surgimiento de las organizaciones de mujeres, he propuesto tres momentos específicos. El primero de ellos en las postrimerías de los 90 e inicios de la década del 2000, en el cual las organizaciones y asociaciones negras-afromexicanas-sobre todo México Negro y África AC- se concentran en mostrar y argumentar por diferentes vías la presencia contemporánea de dichos pueblos así como sus prácticas particulares vinculadas a las expresiones culturales, esto con el objetivo de buscar el reconocimiento constitucional que también buscaban diferentes pueblos y organizaciones indígenas marcadas por las discusiones en los acuerdos de San Andrés, Chiapas.

La segunda ola del movimiento (la primera y segunda década de los 2000) está signada por el trabajo centrado en el reconocimiento constitucional y suma la demanda de realizar una pregunta específica en el censo nacional 2010 sobre la población negra-afromexicana, con el 
objetivo de conocer estadísticamente el estado de este segmento. Estas organizaciones entre las que podemos señalar a la Organización Para el Desarrollo Social y Productivo de los Pueblos Indígenas y Comunidades Afrodescendientes, asociación civil (Socpinda), en este momento también se involucra Ecosta (aunque trabaja otros temas); Enlace de Pueblos y Organizaciones Costeñas Autónomas (EPOCA), y el Colectivo Nacional Afromexicano (Conafro). Uno de los puntos centrales en estas organizaciones es la importancia que cobró entre ellas el tema de la financiación pública y privada de proyectos de desarrollo comunitario, ya que en muchos casos funcionaron como intermediarias.

Como tercer momento temporal y político propongo pensar la aparición de organizaciones de mujeres (2014 en adelante) que pondrán el acento en las diferentes problemáticas de las mujeres en la región costa de Oaxaca al tiempo que las activistas revalorizan su trabajo en la concreción del movimiento y buscan espacios de reconocimiento del mismo.

Volviendo a la historia de vida, es fundamental hacer hincapié en las actividades de Juliana Acevedo en su entorno local, pero también en el ámbito de los diferentes grupos políticos vinculados al reconocimiento de la población negra-afromexicana, primero como una activista histórica, dado que desde su infancia participa en una asociación civil, grupos eclesiásticos y ecologistas y después, porque funda una organización feminista. Por otro lado, el carácter de intelectual que busca generar nuevos significados sobre las fronteras de ser o no ser negraafromexicana más allá de la Costa Chica, más allá del color de piel e, incluso, más allá de los discursos que les vinculan con la esclavitud como único camino de la memoria sobre su genealogía.

\section{Lo íntimo como espacio político de lo femenino}

El espacio íntimo de la narración de una vida proviene de una forma peculiar de comunicación que es la charla: a veces ésta se da en la sala de una casa, en las inmediaciones del fuego de la cocina, al final de una jornada de trabajo o después de una discusión política; también en las pausas de los eventos políticos, en un sinfín de espacios. Pero en este escrito me refiero a dos dimensiones de la historia: la primera de ellas es observar cómo una mujer negra de la Costa Chica de Oaxaca camina las veredas de la participación política y la construcción ontológica de ser negra, es decir, qué significa y cómo narramos ser mujer negra-afromexicana en México. La segunda dimensión de esa misma historia está ligada a los procesos políticos de emergencia étnica de la población negra-afromexicana y la creación de conocimiento en ese medio, así como para su propia identidad diferenciada.

Así, a partir de la historia de vida de Juliana Acevedo, trabajo estas dos dimensiones como posibilidad de comprender y comunicar el largo camino de la lucha de las mujeres negrasafromexicanas por el reconocimiento de su existencia, la posibilidad de su escucha y la potencialidad/radicalidad de un proceso político que en 30 años ha logrado desestabilizar nociones tan cotidianas como el signo común de ser "mexicano o mexicana".

Juliana nació en 1979 en José María Morelos, Huazolotitlán, Costa Chica de Oaxaca. Tiene una hija de 15 años y es madre soltera. Su padre es campesino y su madre se dedica también al campo, al trabajo doméstico y al cuidado de su familia. Tuvo dos hermanos varones, quienes fallecieron "uno al nacer y el otro de cáncer" (ACEVEDO, entrevista personal, enero 2019) y una hermana mayor, quien tiene como oficio la panadería y el cuidado doméstico. Juliana terminó los estudios de Derecho en la Universidad Autónoma Benito Juárez de Oaxaca y tiene formación en diferentes oficios.

Morelos, su pueblo natal y de actual residencia, se encuentra a unos 60 minutos de Pinotepa Nacional, una de las cidades más importantes de la región oaxaqueña, haciendo el recorrido en una camioneta colectiva. Tiene 2,331 personas, y según datos del Instituto Nacional de Estadística, Geografía e Informática (INSTITUTO NACIONAL DE ESTADÍSTICA Y GEOGRAFÍA (INEGI); CONSEJO NACIONAL PARA PREVENIR LA DISCRIMINACIÓN (CONAPRED); COMISIÓN NACIONAL DE LOS DERECHOS HUMANOS, 2017) tiene un grado de rezago social alto en el ámbito rural. Según la Encuesta intercensal de ese mismo organismo, Morelos se encuentra dentro de uno de los municipios con 10 $\%$ y más de población afrodescendiente en México.

Los padres y la hermana de Juliana estudiaron hasta el nivel primaria y ella, como escribí antes, es abogada. Acevedo dice que su familia es original de Morelos y que tiene "raíces mixtecas (indígenas) por parte de su abuelo paterno, provenientes de la zona de Tlaxiaco, entonces tengo sangre mixteca; y por mi abuela paterna, tengo sangre negra de Santo Domingo Armenta, de La Llanada":

Cuando todavía vivía mi bisabuela, quien vivió más de cien años y habitaba en Collantes no tenía el interés y la madurez como sí lo tengo ahora de conocer sobre mis raíces, que ahora sí me causan incertidumbre, la necesidad de saber hasta dónde llegan, pero ahora no hay la biblioteca para saber hasta dónde se quemaron esos libros. Al morir mi abuela y mi bisabuela, sus relatos fueron vidas que se quemaron y ahora es muy difícil recuperar esa información". (ACEVEDO, entrevista personal, enero 2019) 
La violencia social y de género ha marcado también los recuerdos de su infancia, que se mezclan con un pasado ligado a la vida del campo:

Jugaba con los hijos de las personas que trabajaban en el corte de limones; fue una infancia feliz en el campo, entre cosas buenas. También me tocó violencia porque a finales de los 80 y principios de los 90 todavía me tocó ver el rapto 4 de una mujer y no me refiero a la huida o jullida, como lo confunde mucha gente, sino que era llevada a la fuerza, con lujo de violencia y nadie hizo nada por ayudarla [...] esto lo vi enfrente de mi casa. Fue un poco tarde, la chica a la cual se llevaron trabajaba en una cantina, pero eso no le daba la libertad a la persona que se la llevó para hacer eso: prácticamente la fueron desnudando al jalonearla para poder llevarse, como iban armados, nadie quiso ayudar. Lo de la violencia que viví fue así no como la del narco de ahora, eran problema focalizados entre familia". (ACEVEDO, entrevista personal, enero 2019)

Así, la violencia de género marcó la vida de Juliana, ya que diferentes mujeres en su entorno vivieron violencia machista, lo cual se quedó en la memoria de Acevedo y se constituirá como uno de los motores de su activismo.

Los estudios que cursó Juliana los llevó a cabo en instituciones educativas en Morelos: la primaria, la secundaria y la preparatoria por cooperación. Por motivos personales relacionados con el fallecimiento de su hermano, Acevedo dejó de estudiar cuatro años después de terminar la secundaria, y después se trasladó a Oaxaca con el objetivo de sentirse mejor y buscar diferentes caminos vitales, por lo cual estudió durante un semestre en un colegio de monjas:

Aprendí muchas cosas. Me prepararon como preparaban antes a las mujeres para que buscaran un marido, es decir, que yo supiera hacer comida, postres, tejer, bordar. Me sentía como en la época de la colonia. También allí me formaron como catequista. También allí vi la cuestión social, el apoyar al que menos tiene. (ACEVEDO, entrevista personal, enero 2019)

Juliana tiene una visión crítica respecto a la forma en la cual fue educada en ese espacio religioso y en general, respecto a la idea que tiene un profundo arraigo en Morelos: la búsqueda de marido como un elemento central en la vida de las mujeres, a quienes desde pequeñas se les inculca esta idea con el objetivo de que contraigan matrimonio, como señala Marcela Lagarde:

Todas las mujeres por el sólo hecho de serlo son madres y esposas. Desde en el nacimiento y aún antes, las mujeres forman parte de una historia que las conforma como madres y esposas. la maternidad y la conyugalidad son las esferas vitales que organizan y conforman los modos de vida femeninos, independientemente de la edad, de la clase social, de la definición nacional, religiosa o política de las mujeres. (LAGARDE, 2005, p. 363)

Para Juliana el interés en casarse joven como la mayoría de sus congéneres no era mucho:

Decidí irme a Oaxaca a estudiar derecho porque ni en el pueblo o en la zona había posibilidad de estudiar esa carrera. Y porque nunca fue mi sueño casarme, de hecho, en ese inter un chico vino a pedirle mi mano y le dije a mi padre que si él se iba a casar con el chico pues entonces que él le diera la mano, porque yo no: si usted se quiere casar, pues cásese. (ACEVEDO, entrevista personal, enero 2019)

Este enfoque crítico sobre qué significa ser madre soltera o la validación social por ser esposa está presente en las reflexiones de Acevedo. En las diversas charlas informales que preceden este trabajo, Acevedo piensa el papel definitorio de la familia ampliada en los procesos de construcción de comunidad y también en el sentido de la constitución de la identidad negraafromexicana, dado que, como señala sus ancestros, "probablemente vinieron de algún lugar de África, pero mi vida política, económica y social se mantiene gracias a la solidaridad y el amor incondicional de mi familia" (ACEVEDO, entrevista personal, enero 2019). Es decir, para Acevedo ser madre soltera con una familia ampliada la conecta directamente con su ancestría africana y, por ende, marca su subjetividad en términos políticos.

En el ámbito laboral, Juliana también trabajó como empacadora y almacenista en la fábrica de aceite de limón de su pueblo al volver de Oaxaca capital. Después de esto, en Morelos se había implementado la preparatoria por cooperación, a la cual ingresó con el apoyo económico de su familia. Asistía en las tardes a la escuela, y por las mañanas trabajaba en la producción de radio El Cimarrón.

En términos del acceso al trabajo, la actividad de Juliana hace sentido con las estadísticas dadas a conocer por el INEGI en 2017 sobre población afrodescendiente, en cuales señala que:

De acuerdo con estos conceptos, la PEA afrodescendiente tiene una participación en el mercado de trabajo casi tres puntos porcentuales más que la nacional: 53.0 y $50.3 \%$, respectivamente.

\footnotetext{
${ }^{4}$ La diferencia entre rapto y huida es básicamente que, en el caso de la primera, el varón decide llevarse a una mujer que ha elegido sin acuerdo previo entre ambos, puede ser una mujer que ni si quiera ha hablado con él. En el caso de la huida, es una forma de institucionalizar una pareja ante los ojos del pueblo, pero éste hecho sí es consensado, planeado por la mujer y el hombre y después, festejado por la familia como una forma de parentesco reconocida.
} 
Mientras que la PEA de los municipios con 10\% y más de población afrodescendiente presenta el porcentaje más bajo con una participación laboral de $41.9 \%$, es decir, alrededor de ocho puntos porcentuales abajo del nivel nacional. (INEGI, 2017, p. 61)

Esta información da cuenta de lo que las asociaciones y organizaciones afrodescendientes denuncian desde hace más de tres décadas: además del olvido en términos de historia, la población negra-afromexicana se encuentra abandonada por las políticas estatales y privadas en lo que refiere a la inversión social y económica para el desarrollo de la región. La disparidad económica y el empobrecimiento de estas poblaciones es uno de los elementos que históricamente ha afectado a la región.

La situación económica de la mayoría de las personas que participan en el movimiento -y específicamente de las mujeres- es una de las preocupaciones que está presente en las charlas, en las agendas, pero que en pocos espacios públicos se enuncia claramente. En el evento realizado en julio de 2018 para conmemorar la vida de las mujeres afrolatinoamericanas, Juliana fue muy insistente en la cuestión de gestionar de forma autónoma todo el proyecto. Asegura que es importante iniciar la construcción de autonomía y participación comunitaria y dejar de lado la política que convoca a la ciudadanía solo por "apoyos económicos, regalos o comida"; es necesario impulsar proyectos que nazcan desde y para las comunidades, así los intereses partidarios quedarán de lado, asegura.

Esta postura política que es poco vista en las diferentes organizaciones tiene efectos en su vida personal ya que, asegura:

Estoy afectando económicamente a mi familia por mis ideas. Hay muchos (líderes) que se aprovechan y solo quieren sobresalir, ojalá quisieran luchar convencidos y no solo simular. Eso es lo que a veces a mí me decepciona del movimiento, pero he estado pensando que es momento de dejar que otros líderes sigan con el movimiento y lo lleven a feliz término y yo enfocarme a lo importante: mi familia y yo. Creo que lo que he aportado ha sido bastante, que le he dado mucho al movimiento. (ACEVEDO, entrevista personal, enero 2019)

Entre las organizaciones el tema de los fondeos económicos, los recursos estatales administrados por algunas asociaciones, los apoyos de organizaciones no gubernamentales de México y otros países han sido generadores de diferencias al interior del movimiento. Juliana es independiente dado que, como la mayoría de los y las activistas negras-afromexicanas, además de su militancia política tiene un trabajo que le permite obtener ganancias económicas para poder sustentar su vida y la de su hija:

Durante mi estancia en Oaxaca, mientras estudié aprendí a hacer bolsas de vinil para enviar dinero a mi hija, me pagaban a dos pesos la bolsa y hacía unas 70 bolsas al día, durante toda una jornada de trabajo. Además, estampaba, cosía y hacía tortillas para vender, todo para poder viajar cada 15 días a ver a mi hija. Hacía de todo para estar con ella. Decidí volver a Morelos en 2010, cuando mi hija se enfermó y empecé a trabajar vendiendo manualidades. En el pueblo no he podido ejercer como abogada porque la gente todo lo toma muy personal, entonces eso le causa escozor a mi familia, se preocupan de que me pueda pasar algo. Sin embargo, hay gente que se me acerca y pues les he dado asesorías legales, pero me he dedicado a todos los oficios que aprendí. (ACEVEDO, entrevista personal, enero 2019)

Juliana empezó desde pequeña su participación política a lado de la organización África AC, que tiene su cara más visible con el profesor Israel Reyes. África centró sus esfuerzos en la gestión cultura y la visibilización de la danza, música y expresiones culturales de la población negra-afromexicana de Oaxaca, específicamente de los diferentes pueblos del distrito de Jamiltepec. Ante la pregunta de cómo inició su participación política, Acevedo dice:

Yo nunca me he encuadrado en los roles de género asignados. Nunca me ha gustado ser pasiva sino parte activa de algo, no sirvo para acatar órdenes. (ACEVEDO, entrevista personal, enero 2019)

Es central pensar en las diferentes formas en las cuales se ha representado a las mujeres no mestizas (indígenas y negras-afromexicanas) en términos de la participación políica más allá de lo institucional, en ese sentido las mujeres indígenas zapatistas fueron pioneras al salir de las representaciones racistas y racializantes, ya que:

El zapatismo contemporáneo ha exacerbado el campo enunciativo de y sobre las mujeres indígenas, provocando un salto en su autoconciencia y sus autorepresentaciones y ayudando a consolidar su agencia. Esto lo podemos constatar en el acrecentamiento de su horizonte de visibilización. (Márgara MILLÁN, 2014, p.67)

Tanto para el movimiento negro-afromexicano como para la discusión respecto al papel de las mujeres en éste, el neozapatismo ha sido una referencia en diferentes momentos, sobre todo en lo que se refiere a la participación de sectores alterizados en las políticas nacionales. Por otro lado, para el movimiento afrodescendiente en América Latina, las reflexiones del black feminism y el 
feminismo negro latinoamericano, han impactado de forma particular en las narrativas y las prácticas políticas de las activistas, quienes reconocen las intersecciones de los procesos de racialización:

El feminismo descolonial elabora una genealogía del pensamiento producido desde los márgenes por feministas, mujeres, lesbianas y gente racializada en general; y dialoga con los conocimientos generados por intelectuales y activistas comprometidos con desmantelar la matriz de opresión múltiple asumiendo un punto de vista no eurocentrado. (Yuderkis ESPINOZA, 2014, p.8)

En esta historia de vida, las palabras de Yuderkis Espinoza resuenan, ya que el camino recorrido por Juliana está marcado por las diferentes formas en cuales se construyó su experiencia como mujer negra. Su subjetividad está entrelazada con la participación política que ha tenido desde niña:

Desde la primaria tuve un acercamiento con el movimiento a través del profesor Israel Reyes Larrea, porque era mi profesor de la primaria. Allí empecé a involucrarme con pirograbado y después en la secundaria con el centro de producción de radio en Morelos, esto cuando tenía 11 o 12 años, allí fui capacitada como radialista. Así que mientras Israel estaba hablando en el micrófono yo era la que estaba tras los controles grabando el programa de radio de Cimarrón. Siempre participé en las actividades que iba haciendo Israel. (ACEVEDO, entrevista personal, enero 2019)

La organización África AC se dedica a la gestión cultural y al activismo político desde el posicionamiento y reivindicación de la cultura costeña. Israel Reyes, el fundador, trabaja desde hace más de 30 años con diferentes grupos de danza y música en la región oaxaqueña, y Juliana empezó así su activismo, por eso señaló anteriormente que ella jamás ha estado solo en los espacios históricamente sancionados a las mujeres:

En Morelos iniciamos trabajando con encuentros de danza, mucho antes de lo del Encuentro de Pueblos Negros se llamaba encuentro de danza y música indígena y negra; se transmitía por la estación de radio La voz de la Costa Chica; a mí por lo general me tocaba conducir esos programas a pleno rayo del sol en la cancha del pueblo, que entonces no estaba techada. Entonces era una cuestión bonita y emocionante poco a poco se han ido ampliando los horizontes y las actividades, pero en ese momento era, desde mi vivencia, solo un rescate cultural el recobrar de dónde venía. Antes de que El Cimarrón fuera en radio era en papel y allí publiqué mi primer poema. (ACEVEDO, entrevista personal, enero 2019)

Juliana se mudó a la capital del estado para estudiar derecho y continúo participando en las actividades políticas en su pueblo:

Cuando había algunas cosas venía [a Morelos] y en las vacaciones me ponía a hacer cosas. Nunca lo he dejado, hasta ahora que estoy pensando ciertamente el dejarlo, pero siempre ha sido parte de mi vida. Creo que lo que me motivó a participar desde pequeña fue el racismo y la discriminación vividas y ahora que tengo a mi hija pues por ella, por heredarle una forma diferente de vivir. (ACEVEDO, entrevista personal, enero 2019)

Si bien Juliana ha vivido experiencias en las cuales se le discrimina, su recuerdo de la capital oaxaqueña está imbricado fuertemente con estas prácticas hacia ella. En las diferentes charlas y en la entrevista aseguró que en la Costa sí ha sentido discriminación, pero cuando se refiere a la larga estancia que tuvo en la ciudad, asegura que fue un espacio en el que vivió agresiones racistas por sus características fenotípicas racializadas y origen étnico.

\section{Racismo y discriminación}

Al leer los primeros documentos y discursos de las diferentes organizaciones negrasafromexicanas, es posible reconocer dos líneas en lo que respecta al racismo y a la discriminación. Los señalamientos sobre la nula representación del pueblo negro-afromexicano en las narraciones históricas públicas (libros de texto y divulgación), así como en los trabajos académicos, son parte de una denuncia sobre el racismo con el cual se ha abordado la existencia de estos pueblos desde el siglo XIX en México.

Los argumentos sobre discriminación y racialización enunciados se relacionan con las formas en las cuales la ciudadanía y representantes de instituciones gubernamentales encuentran en la existencia pública de las personas negras-afromexicanas una extranjería o anormalidad en el panorama racializado de la ciudad. Esta visión de extranjería está construída sobre la base de la ideología del mestizaje entre indígenas y españoles:

Me pasó algo similar a lo de Victoria Santa $\mathrm{Cruz}^{5}$ cuando mi hermano me llevó a la ciudad de Oaxaca. Aquí en la costa no sentía ese racismo y discriminación como lo sentí saliendo

\footnotetext{
${ }^{5}$ Victoria Santa Cruz (1922-2014) fue una coreógrafa y compositora afroperuana que fundó el grupo de danza Perú Negro, que buscó visibilizar a dicha población a través de la danza. Su famoso poema Me gritaron negra, es declamado en diferentes encuentros en la Costa Chica desde que se inició el movimiento político afromexicano.
} 
de aquí. Me decían "colochita ¿de dónde eres? ¿De Veracruz, de Cuba? ¿de dónde eres? porque no pareces de aquí". A partir de eso quise saber el por qué, empecé a preguntar y mi mamá me decía que nuestra abuela era de Collantes y por eso teníamos familia negra pero no había más allá, más información. Pero aquí en la costa no lo sentí tan horrible como al salir, allí fue donde me di cuenta que había diferencias: saliendo de la Costa Chica, en la ciudad de Oaxaca ni siquiera en otro estado. Allí he enfrentado un montón de actos de discriminación y de racismo, durante toda mi vida, ha sido parte de mi vida y eso tal vez también ha hecho que vea a esta lucha desde una perspectiva diferente porque a mí sí me pega y no quisiera que otra persona lo sufriera y mis ideas guajiras han sido más hacia lo colectivo que hacía lo individual. (ACEVEDO, entrevista personal, enero 2019)

En la voz de Juliana podemos escuchar cómo los procesos de la discriminación, el racismo y la racialización se conjuntan en una experiencia que se convierte en su potencialidad política. Primero, porque es marcada como de otro estado, de otro país, por su fenotipo racializado en una ciudad donde éstos fenotipos se normalizan a través de los estereotipos sobre lo indígena, lo mestizo y lo extranjero (blanco, en su mayoría), es decir es discriminada al excluirla como una mujer no oaxaqueña. Segundo, porque a partir de esa identificación estereotipada y racializada, Juliana es tratada en el espacio público como otra, es excluida: hipersexualizada, acosada, es decir, mostrada a partir de ciertos rasgos específicos que se concatenan a partir de las narrativas históricas y públicas sobre qué debe ser y cómo debe ser una mujer negra en México.

Por último, Juliana echa mano de su experiencia en el movimiento para narrar este racismo como aquello que la anima a seguir participando e imaginando otro tipo de relación social que no esté fincada en el racismo estructural que a ella como a miles de hombres y mujeres negrosafromexicanos se les ha impuesto. En ese sentido, Aura Cumes escribe de la construcción histórica de las mujeres mayas como sirvientas, sobre experiencias corporalizadas y marcajes racistas:

Las mujeres indígenas no solo son vistas como sirvientas porque trabajen muchas de ellas, en casa particular, sino que aun cuando nunca han hecho este oficio, son imaginadas como tales especialmente en las áreas metropolitanas. Cuando a las mujeres indígenas se les detiene en la calle para ofrecerles trabajo, están sufriendo acecho; sus cuerpos se ven como expropiables, utilizables, como el de la mayoría de indígenas mujeres pero también hombres. Pero verlas como sirvientas, parece no ser I problema más grave, sino que a través de ello, se les degrada, segrega, se les trata violencia racista y ante todo, se les busca "colocar en su lugar", el lugar que la historia colonial les ha destinado. (Aura CUMES, 2014, p.129)

Para las mujeres negras-afromexicanas el lugar designado no es solo el de la servidumbre, sino que el estereotipo que se repite en casi todo el mundo tiene que ver con la disponibilidad sexual que supuestamente tienen estas mujeres, con la idea de que sus cuerpos son depositarios de la fantasía de la raza:

En el plano epistemológico, negro no designa a simple vista una realidad significante, sino un yacimiento $\circ$, mejor dicho, una ganga compuesta de tonterías y de fantasías urdidas por Occidente y otras partes del mundo; tonterías y fantasías con las que fue revestida la gente de origen africano mucho tiempo antes de que cayera en las redes del capitalismo emergente de los siglos XV y XVI. (Achille MBEMBE, 2016, p.84)

Juliana no ha sido la excepción a esta regla:

En la ciudad de Oaxaca me molestaba el hecho de que algunos se me acercaran por ser negra, por la idea de fogosidad y todo eso. Eso era terrible, incluso fui acosada toda la carrera por un profesor, quien incluso llegó a ofrecerme de manera indirecta dinero. Algunas chicas de la Costa sí aceptaron ese papel de mujeres de fuego, sin embargo, yo siempre hui de ser tratada así. (ACEVEDO, entrevista personal, enero 2019)

Si bien Juliana participa del movimiento negro-afromexicano desde su niñez y juventud, estas experiencias de racismo unidas a la maternidad le permiten observar diferencias entre la demanda por el reconocimiento de su identidad cultural para, poco a poco, pensar en cuáles son las especificidades de la vida de las mujeres negras-afromexicanas en la Costa Chica de Oaxaca. Ya instalada en la capital del estado y al finalizar sus estudios, Acevedo entra de lleno en el mundo del trabajo, sobre todo para agencias del gobierno estatal como la Secretaría de Finanzas, el Tribunal Superior de Justicia y la Secretaría de Desarrollo Social (Sedesol); el único trabajo vinculado a su participación política fue el cargo ocupado entre 2015 y 2017 en la Secretaría de Asuntos Indígenas del estado de Oaxaca (SAl), en el área de atención a mujeres indígenas y afromexicanas:

Allí hice acompañamiento y casos, desde la SAl se apoyó el encuentro de mujeres afro en la costa. Se trató de impulsar el 25 de julio (día de la mujer negra y afromexicana); hice cosas enfocadas a los diferentes grupos de activistas en la región de la Costa Chica. Allí realizamos un módulo de la Cátedra de la Escuela Itinerante de Mujeres Negras, previo a la Escuela Itinerante. Esa Escuela Itinerante fue organizada por la red de mujeres indígenas y nos vinculó con la Red de Mujeres Afrolatinoamericanas, Caribeñas y de la Diáspora porque estaban 
por lanzar su plataforma con miras al decenio internacional afrodescendiente. (ACEVEDO, entrevista personal, enero 2019)

El trabajo, pero sobre todo la mirada enfocada en la situación, problemas y trabajo de las mujeres negras-afromexicanas, estaban para 2015 muy claros en el compromiso y el pensamiento de Juliana. Sin embargo, y aunque desde hace más de siete años el tema está siendo debatido, en las organizaciones se perpetúan las ideas de que las mujeres no participan políticamente, sino que sólo apoyan. A pesar de este pensamiento que no sólo se encuentra en las plataformas afrodescendientes, las mujeres trabajan, son parte activa y fundamental de cada uno de los encuentros políticos siempre desde las actividades determinadas por los roles de género:

Desde 2012 hasta ahora he visto que entre las organizaciones negras-afromexicanas el tema de las mujeres queda relegado, los machirrines siempre ponen sus intereses enfrente y las mujeres namás ayudan y hasta allí. No había ese papel activo y a mí me repateaba el hígado. Yo no he sido una mujer que he estado tras bambalinas, he sido una mujer que siempre ha tratado de posicionarse, que no le gusta que le dicten qué hacer. Yo quisiera que las otras mujeres se dieran cuenta que tienen ese poder... eso y el ver que se la pasaban cocinando, atendiendo y les preguntaba ¿a qué hora se integran? Al rato, me decían y les comentaba a las que estaban en la cocina, pero es que ustedes también necesitan estar, necesitan hablar. No es un proceso fácil porque están muchos roles bien cimentados y el miedo a que mi voz no sea tomada en cuenta porque yo como mujer no tengo mucho que aportar como los otros. Aunque sea decir "el mole se prepara de esta manera" es parte de nuestra gastronomía y de nuestra cultura, como para incentivarlas. (ACEVEDO, entrevista personal, enero 2019)

Si bien es cierto que las mujeres han sostenido con su trabajo la participación política de los varones que públicamente aparecen como líderes, es hasta hace poco tiempo que los aportes de las mujeres empiezan a ser valorados por las diferentes activistas. Una de las estrategias utilizadas por el movimiento en general fue el uso de tradiciones como la Danza de los Diablos para mostrarse al exterior (a la sociedad mexicana) y al interior de los pueblos iniciar procesos de etnogénesis (VARELA, 2014). Tanto Juliana como otras mujeres de diferentes edades y pueblos continúan trabajando desde esa perspectiva para organizarse colectivamente frente a las muchas violencias que las atraviesan:

También formé un club de danza donde sacamos una danza africana; además hice un grupo de danza para hablar con las mujeres sobre sus derechos, porque si las citas para pláticas te mandan a la goma... entonces lo que hice fue crear un espacio en el que ellas pudieran recrearse y olvidarse de cosas de la casa y fue así que se hizo un grupo grande, lo presentamos el 20 de diciembre de 2015, todo lo que trabajamos... entre número y número de poesía y baile hablábamos de derechos de las mujeres con toda la comunidad que se reunía: de las violencias que existen, de la diferencia entre sexo y género, algo que resultaría muy difícil sino es a través de la cultura. Sirvió como espacio de catarsis para personas que se encontraban en problemáticas más duras. (ACEVEDO, entrevista personal, enero 2019)

Desde el 2018, Juliana impulsa la Organización para el Fomento de la Equidad de Género y Respeto de los Derechos Humanos de los Pueblos Negros-Afromexicanos (OFPNA), con la que ya organizó dos foros: uno el 8 de marzo de 2018 y otro el 25 de julio de 2018 :

En ambos foros buscamos que fueran autónomos y cercanos a la comunidad que es una de las miras que siempre he tenido, tratar de generar conciencia entre la gente, de la importancia de conocer sus derechos y de exigirlos y no solo tener portavoces, sino ser ellos sus propios voceros. Son intentos, todavía vamos en vías de, es un camino muy largo para poder lograr eso sí es que algún día se logra. (ACEVEDO, entrevista personal, enero 2019)

La postura de Juliana es trabajar con el Estado como interlocutor, pero no como gerente de la diferencia cultural que buscan mostrar como organizaciones negras- afromexicanas. Durante nuestros encuentros en Oaxaca y la costa, siempre enfatiza la necesidad de trabajar con la gente de los pueblos, puesto que es con esta población con quien le gustaría caminar:

Los retos para el movimiento son muy complejos y no sé si puedan salvar. Uno de ellos es quitar la mirada individualista de las organizaciones, dejar de verlo como qué puedo sacar sino qué puedo aportar, creo que eso no se ha entendido en el movimiento. Además de lograr dejar de ver solo las diferencias individuales y ver lo colectivo, ver más lo que nos une. Pero para mí lo principal es trabajar hacia dentro, hacia la comunidad. Es necesario trabajar al interior de las comunidades para poder vernos, para poder encontrarnos. El tema de identidad debería abonar a los pueblos negros, por eso hay que buscar estrategias para poder llegarle a la gente. (ACEVEDO, entrevista personal, enero 2019)

Para Juliana y para otras mujeres negras-afromexicanas es importante hacer notar su valor más allá de los estereotipos asociados a sus cuerpos. En el ámbito de la participación política, por otro lado, consideramos importante hacer notar que la barrera que en algunas ocasiones se 
impone además de los liderazgos masculinos, es la división entre aquellos sujetos que actúan y aquellos que piensan. Juliana Acevedo junto a otras mujeres negras-afromexicanas han dotado de sentido y contexto al movimiento político, es decir, se han convertido en las intelectuales dentro de esta movilización. Siguiendo las ideas de Patricia Hill Collins (2000), podemos asentar que:

Desarrollar el pensamiento del feminismo negro también involucra una búsqueda por su expresión en espacios institucionales alternativos y entre mujeres que no son percibidas comúnmente como intelectuales. Como he definido, las mujeres negras intelectuales no son todas académicas ni se encuentran en la clase media negra. En lugar de eso, son todas las mujeres negras de los Estados Unidos que de alguna forman contribuyen a generar un pensamiento feminista como teoría social crítica quienes son considerada como intelectuales. Pueden tener mucha educación formal. Algunas no. (HILL COLLINS, 2000, p.14) ${ }^{6}$

Así, el pensamiento feminista de Juliana está marcado por la circulación del pensamiento negro de Estados Unidos, pero también por los discursos de los llamados feminismos indígenas en Latinoamericanos:

También es necesario ver las cosas desde los beneficios para hombres y mujeres, que no se vea solo como la lucha de las mujeres, sino que haya un acompañamiento de ambos. Que el tema de las mujeres no sea un discurso repetido, que también nosotras necesitamos que se nos dé importancia porque muchas veces los compañeros se mofan de lo que hacemos y decimos las mujeres. Deberíamos poder avanzar en bloque. (ACEVEDO, entrevista personal, enero 2019)

Esta implicación de los varones negros-afromexicanos en la discusión de la situación de las mujeres negras-afromexicanas es cercano al pensamiento del feminismo negro, que tuvo como epicentro el movimiento por los derechos civiles de la población afro en la década de 60 en los Estados Unidos, y específicamente hacía un marcaje no sólo sobre la condición de las mujeres en el patriarcado, sino sobre las mujeres negras en el patriarcado, que intrínsecamente está basado en el racismo como modo de dominación capitalista, en el mismo sentido que las ideas de las feministas afroestadounidenses:

Aunque somos feministas y lesbianas, sentimos solidaridad con los hombres negros progresistas y no defendemos la fragmentación que exigen las mujeres blancas separatistas. Nuestra situación como gente negra requiere que tengamos una solidaridad por el hecho de ser de la misma raza, la cual las mujeres blancas por supuesto no necesitan tener con los hombres blancos, a menos que sea solidaridad negativa como opresores raciales. Luchamos junto a los negros contra el racismo, al mismo tiempo que también luchamos contra los hombres negros por el sexismo. (COLECTIVO COMBAHEE RIVER, 1988, p. 16-17)

Las mujeres negras-afromexicanas están luchando junto a sus compañeros, pero también dentro de esos espacios para impulsar la discusión sobre relaciones de poder y subordinación que afectan a las niñas y mujeres afromexicanas. Como el queridato, una forma de relación de parentesco que teóricamente permite que los varones en comunidades negras-afromexicanas puedan tener una esposa formal y una pareja que no implica casamiento, pero sí es conocida por la comunidad como la querida. En el caso específico de Juliana esa figura de parentesco está imbricada con la violencia en su casa:

El queridato para mí es una figura nefasta, una figura que ha generado muerte al interior de mi familia porque mi abuelo mató a mi abuela materna (su esposa) precisamente a raíz de eso. Me cuenta mi madre que a ella le contaron, porque tenía dos meses de edad cuando esto ocurrió, que mi abuela Felicidad fue abordada por la señora (la querida) a donde Felicidad iba a traer agua y le dijo de cosas; mi abuela, como era de pocas pulgas, le pegó a la querida, entonces cuando mi abuelo fue a ver a la querida, iba para la milpa y la querida le dijo llorando que mi abuela felicidad la había agredido. Él se regresó a la casa de mi abuela, ya no fue a la milpa. Empezaron a discutir y le quería pegar, entonces en la discusión y en el calor de todo se metió una de mis tías, a mi abuelo quien aventó y le lastimó la mano. Estaba tan enojado que amagó a mi abuela Felicidad con el arma para que se detuviera, pero se le fue el tiro y le dio en el corazón, entonces las mujeres decían que estaba en un charco de leche y sangre porque iba a dar de amamantar a mi mamá, eso fue en 1946. (Acevedo, entrevista personal, enero, 2019)

Durante el trabajo de campo realizado para esta investigación, escuché historias de violencia en la niñez de las activistas e intelectuales vinculadas con el queridato. Quienes hablaron de esto en relación con su niñez e incluso en su vida de pareja, no viven el queridato como una

\footnotetext{
${ }^{6}$ Developing Black feminist thought also involves searching for its expression in alternative institutional locations and among women who are not commonly perceived as intellectuals. As defined in this volume, Black women intellectuals are neither all academics nor found primarily in the Black middle class. Instead, all U.S. Black women who somehow contribute to Black feminist thought as critical social theory are deemed to be "intellectuals." They may be highly educated. Many are not. (traducción personal)
} 
forma de parentesco, sino como una forma de sujeción de las mujeres a los maridos, porque el sistema social les inculca desde la niñez que una mujer -como dijo Juliana al principio de este artículo- no tiene valor ni espacio social.

Para Juliana, como para diferentes mujeres activistas/ intelectuales, el queridato debe ser repensando no como una forma de reconocimiento de la etnicidad negra-afromexicana, sino como una de las formas de control social hacia las mujeres, por lo cual se encuentran trabajando en denuncias sobre violencia contra la mujer que no solo se centre en la violencia física. En el caso específico de Juliana, la violencia del queridato terminó con el asesinato de su abuela. Hoy, para ella, el activismo es una forma de dignificar a su abuela asesinada.

\section{Conclusiones}

Juliana Acevedo publicó en 2018 un libro sobre los derechos de los pueblos negrosafromexicanos para la Suprema Corte de Justicia de la Nación, una investigación que realizó en diferentes pueblos de la región, recabando información sobre la tenencia de la tierra, la situación de las mujeres, la lucha por el reconocimiento y el pluralismo jurídico. En ese texto (ACEVEDO, 2018) da cuenta de un proceso de largo aliento del cual ella es parte activa y también es una analista, pensadora para su propio pueblo.

El objetivo de este artículo fue observar a través de la historia de vida de Juliana Acevedo Ávila como el proceso político negro-afromexicano ha sido fundamental para su constitución subjetiva y su actuar político además de sus propuestas analíticas, y podemos asegurar que el proceso de construcción de una identidad negra-afromexicana está mediada por los procesos de racialización y racismo que personas de la Costa Chica han vivido en un largo tiempo histórico, pero es hasta la introducción de políticas multiculturalistas junto con la impronta del movimiento zapatista que se genera una nueva identidad, y con ella, una subjetividad específica como podemos leer en los diferentes pasajes que Juliana compartió para la realización de este documento.

Un elemento importante para la concreción de dicha subjetividad está relacionado con las diferentes reapropiaciones y contextualizaciones de diferentes corrientes del feminismo entre las mujeres de la Costa Chica. Es decir, Juliana discute con Patricia Hill Collins como representante del feminismo negro de Estados Unidos; trae con sus palabras al feminismo decolonial e indígena que pugnan por prácticas y análisis situados, como aquel que expone Yuderkis Espinoza; también se piensa en cómo las mujeres viven diferentes formas de opresión en la vida cotidiana, retomando las ideas del feminismo mexicano de la segunda mitad del siglo XX.

A través de la Cátedra Itinerante de Mujeres Afromexicanas en 2016, activistas se acercan a las diversas teorizaciones y experiencias feministas tanto en el ámbito académico como político para conocer y contextualizar su lucha política. Estas discusiones no son sólo de Juliana, sino de un colectivo de mujeres negras-afromexicanas activistas e intelectuales que se encuentran pensando cómo hacer frente, por ejemplo, a una institución que les cosifica y provoca dolor: el queridato.

Estos debates son novedosos en tanto que circulan entre los movimientos de reivindicación étnica, pero impactan en diversos espacios de los feminismos no urbanos ni académicos, sino construyendo entre espacios indígenas y afromexicanos para dar cuenta de las intersecciones que viven las mujeres de dichas poblaciones.

El recorrido de la vida de Juliana, por otro lado, muestra diferentes formas de racismo, exclusión y empobrecimiento de la población negra-afromexicana en el estado de Oaxaca, pero sobre todo nos muestra cómo las formas de racismo fueron convertidas en un motor para la concreción de la lucha de las personas y colectivos negros-afromexicanos frente a un Estado que ha negado su existencia a través de la invisibilización en todos los espacios públicos.

\section{Referencias}

ACEVEDO ÁVILA, Juliana. Los pueblos negros de México: su lucha por la sobrevivencia cultural y el reconocimiento jurídico. México: Suprema Corte de Justicia de la Nación, 2018.

ALFARO, Mara; SÁNCHEZ, Gustavo. Chacahua: reflejos de un parque. México: Plaza y Valdés, 2002.

CHAKRAVORTY SPIVAK, Gayatri; GIRALDO, Santiago. “¿Puede hablar el subalterno?”. Revista Colombiana de Antropología, Bogotá, v. 39, p. 297-364, enero-diciembre 2003. Disponible en https://www.redalyc.org/pdf/1050/105018181010.pdf. Visitado el 08/05/2019.

CHASSEN-LÓPEZ, Francie. "Biografiando mujeres: ¿qué es la diferencia?" Secuencia, Ciudad de México, n. 100, p. 133-162, enero-abril 2018. Disponible en http://www.scielo.org.mx/scielo.php?script= sci_arttext\&pid=S0186-03482018000100133\&lng=es\&nrm=iso. Visitado el 08/05/2019. 
COLECTIVO COMBAHEE RIVER. Manifiesto: Una declaración negra feminista. In: MORAGA, Cherrie; CASTILLO, Ana (comp). Esta puente, mi espalda. Voces de mujeres tercermundistas en los Estados Unidos. San Francisco: ISM Press, 1988. p. 172-187.

CUMES SIMÓN, Aura Estela. Servidumbre doméstica, colonialismo y patriarcado en Guatemala. 2014. Tesis (Doctorado en Antropología), Centro de Investigaciones y Estudios Superiores en Antropología Social, Ciudad de México, México.

ESPINOZA, Yuderkis. "Una crítica descolonial a la epistemología feminista crítica". El Cotidiano, México, n. 184, p. 7-12, marzo-abril 2014. Disponible en http://www.redalyc.org/pdf/325/32530724004.pdf. Visitado el 08/05/2019.

FEDERICI, Silvia, Calibán y la bruja: Mujeres, cuerpo y acumulación originaria. Madrid: Traficantes de Sueños. 2010.

FERRAROTTI, Franco. "Las historias de vida como método". Convergencia. Revista de Ciencias Sociales de la Universidad del Estado de México, Toluca, v. 14, n 44, p. 15-44, mayo-agosto 2007. Disponible en https://www.redalyc.org/pdf/105/10504402.pdf. Visitado el 08/05/2019.

HILL COLLINS, Patricia. Feminist thought. Knowledge, consciousness, and the politics of empowerment. New York/ London: Routledge, 2000.

INSTITUTO NACIONAL DE ESTADÍSTICA Y GEOGRAFÍA (INEGI); CONSEJO NACIONAL PARA PREVENIR LA DISCRIMINACIÓN (CONAPRED); COMISIÓN NACIONAL DE LOS DERECHOS HUMANOS (Eds.). Perfil Sociodemográfico de la población afrodescendiente en México. México, 2017.

L. GIL, Silvia. Nuevos feminismos. Sentidos comunes en la dispersión. Una historia de trayectorias y rupturas en el Estado español. Madrid: Traficantes de Sueños, 2011.

LAGARDE Y DE LOS RÍOS, Marcela. Los cautiverios de las mujeres. México: Dirección General de Estudios de Posgrado; Centro de Investigaciones Interdisciplinarias en Ciencias y Humanidades y Programa Universitario de Estudios de Género, Universidad Nacional Autónoma de México, 2005.

LAO MONTES, Agustín. "Cartografías del campo político afrodescendiente en América Latina". Universitas Humanística, Bogotá, v. 68, p. 207-245, julio-diciembre 2009. Disponible en https:// revistas.javeriana.edu.co/index.php/univhumanistica/article/view/2273/1579. Visitado el 08/05/2019.

LARA MILLÁN, Gloria. "Negro-Afromexicanos: Formaciones de alteridad y reconocimiento étnico". Revista de Estudos e Pesquisas sobre as Américas, Brasília, v. 8, n. 1, p. 149-175, 2014. Disponible en http://periodicos.unb.br/index.php/repam/article/view/18481. Visitado el 08/05/2019.

MBEMBE, Achille. Crítica de la razón negra. Argentina: Ned Ediciones, 2016.

MILLÁN, Márgara. Desordenando el género/¿descentrando la nación?. El zapatismo de las mujeres indígenas y sus consecuencias (1 a ed.). Ciudad de México: Facultad de Ciencias Políticas y Sociales, UNAM; Instituto de Investigaciones Antropológicas, UNAM; Benemérita Universidad Autónoma de Puebla; Ediciones del Lirio, 2014.

MIRANDA REYES, Mariana. Soy la negra de la costa. La reconfiguración de la identidad de género de mujeres afromexicanas de la Costa Chica. 2012. Tesis (Maestría en Estudios Latinoamericanos), Universidad Nacional Autónoma de México, Ciudad de México, México.

PÉREZ OROZCO, Amaia. Subversión feminista de la economía. Aportes para un debate sobre el conflicto capital-vida. Madrid: Traficantes de Sueños, 2014.

VARELA HUERTA, Itza Amanda. "El papel de las mujeres en el proceso político negro-afromexicano". Dfensor, revista mensual de la Comisión de Derechos Humanos del Distrito Federal, Ciudad de México, n. 7, año XV, p. 22-25, julio 2017. Disponible en https://cdhdf.org.mx/wp-content/uploads/ 2014/05/dfensor_07_2017.pdf. Visitado el 08/05/2019.

VARELA HUERTA, Itza Amanda. "Proceso de identificación de los pueblos negros de la Costa Chica en México: Usos de la cultura en la constitución de su etnogénesis". Intersticios de la política y la cultura/ Intervenciones latinoamericanas, Córdoba, v. 3, n. 5, p. 53-67, 2014. Disponible en https:/ /revistas.unc.edu.ar/index.php/intersticios/article/view/7515. Visitado el 08/05/2019. 
Itza Amanda Varela Huerta (iavarela@colmex.mx) es Profesora investigadora en el Programa Interdisciplinario de Estudios de Género, Centro de Estudios Sociológicos de El Colegio de México. Dra. en Ciencias Sociales por la Universidad Autónoma Metropolitana- Xochimilco; maestra en Estudios Latinoamericanos por la Universidad Nacional Autónoma de México. Investiga temas relacionados con la construcción de identidades y subjetividades negras-afromexicanas en el siglo XX-XXI, feminismo poscolonialidad y procesos políticos y etnicidades.

\section{COMO CITAR ESTE ARTÍCULO, DE ACUERDO CON LAS NORMAS DE LA REVISTA:}

HUERTA, Itza Amanda Varela. "Mujeres y movimiento negro afromexicano a través de la historia de vida". Revista Estudos Feministas, Florianópolis, v. 29, n. 1, e65072, 2021.

\section{CONTRIBUCIÓN DE AUTORÍA}

No se aplica.

\section{FINANCIACIÓN}

Beca posdoctoral otorgada por el Consejo Nacional de Ciencia y Tecnología (México)

\section{CONSENTIMIENTO DE USO DE IMAGEN}

No se aplica.

\section{APROBACIÓN DE COMITÉ DE ÉTICA EN INVESTIGACIÓN}

No se aplica.

\section{CONFLICTO DE INTERESES}

No se aplica.

\section{LICENCIA DE USO}

Este artículo está licenciado bajo la Licencia Creative Commons CC-BY 4.0 Internacional. Con esta licencia se puede compartir, adaptar, crear material para cualquier objetivo, siempre que se le atribuya la autoría.

\section{HISTORIAL}

Recibido el 08/05/2019

Presentado nuevamente el 20/10/2020

Aprobado el 16/11/2020

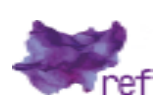

